\title{
RETROBULBAR HAEMORRHAGE: WHEN SHOULD WE OPERATE?
}

\author{
S. AHMED' and M. C. GRAYSON ${ }^{2}$ \\ Dundee and Kirkcaldy.
}

\begin{abstract}
SUMMARY
Retrobulbar haemorrhage ( $\mathrm{RBH})$ is the most common complication of retrobulbar anaesthesia. Following such haemorrhage the patient is traditionally discharged from hospital the following day and readmitted a month or so later to undergo surgery, preferably under general anaesthesia. Such a practice no doubt causes anxiety and disappointment for both the surgeon and the patient. This retrospective study was based at Victoria Hospital, Kirkcaldy, where most of the patients who develop RBH have repeat surgery under general anaesthesia or, if not suitable, under local anaesthesia within $2-4$ days of the incident. The study showed that if certain guidelines are followed, then it is quite safe to proceed with planned surgery soon after the haemorrhage and that long postponement is not necessary.
\end{abstract}

Retrobulbar anaesthesia was first described by Knapp' in 1884. Despite current increasing interest in peribulbar ${ }^{2.3}$ and other forms ${ }^{4}$ of ocular anaesthesia, it is still a widely practised anaesthetic procedure in ophthalmic surgery and in the vast majority of cases has no serious complications. ${ }^{5.6}$ Retrobulbar or orbital haemorrhage $(\mathrm{RBH})$ is its most common complication, and its reported incidence is in the range of $1-3 \% .^{6.7}$

Following such haemorrhage the eyelids become tense and the pressure within the globe is increased. To proceed with surgery in such circumstances is contraindicated, ${ }^{t-8}$ and the procedure is usually postponed. The question of when to re-operate has not been generally addressed. The patients are usually discharged home the following day and re-listed for surgery in a few weeks time, surgery being performed preferably under a general anaesthetic. Cancellation and long postponement of surgery cause disappointment for both the patient and the surgeon.

From: 'Department of Ophthalmology, Ninewells Hospital and Medical School, Dundee; 'Department of Ophthalmology, Victoria Hospital, Kirkcaldy, UK.

Correspondence to: Dr S. Ahmed, FRCS, FRCOphth. Department of Ophthalmology, Ninewells Hospital and Medical School. Dundee DD1 9SY, UK.
Our study was based at the Victoria Hospital, Kirkcaldy, Fife, which is a 664 bedded District General Hospital with 29 ophthalmic beds. In the unit, patients who develop RBH are routinely considered for surgery as early as 2 days after the incident. The aim of our study was to ascertain guidelines to be followed to determine a patient's suitability to undergo intraocular surgery soon after the haemorrhage and to ascertain whether any adverse problems had been encountered in such patients who had undergone planned surgery without long postponement.

\section{MATERIALS AND METHODS}

The case notes of all those patients who had developed RBH during the period March 1985 to March 1992 were retrospectively reviewed. The total number of ocular surgical procedures performed under retrobulbar anaesthesia during this period was also ascertained. All the patients had had pre-operative visual acuity recordings, slit lamp examination, funduscopy and applanation tonometry.

Retrobulbar anaesthesia was delivered with a $40 \mathrm{~mm} 25$ gauge disposable needle using $2 \%$ lignocaine with 1:200 000 adrenaline. The needle was introduced at the junction between the middle and lateral one-third of the lower eyelid and directed towards the muscle cone. Normally 2-3 $\mathrm{ml}$ of the anaesthetic was injected into the muscle cone. Upon noticing RBH, surgery was cancelled and an attempt to visualise the optic disc was made to detect patency of the central retinal artery. The patient then received intravenous acetazolamide $500 \mathrm{mg}$ and a firm eye pad. The following day and subsequently the eye was tested for visual acuity, ocular movement, tenseness of the globe, laxity of the eyelid, resistance to retropulsion and extent of proptosis in relation to the fellow eye, and applanation tonometry was performed. Patients considered suitable for proceeding with planned surgery under general anaesthesia underwent the appropriate work-up.

\section{RESULTS}

Thirty patients developed RBH during the study period. A 
total of 3360 ophthalmic procedures were done under retrobulbar anaesthesia, giving an incidence rate for $\mathrm{RBH}$ of $1.07 \%$. All 36 patients who developed RBH had been considered suitable to have their surgery performed under local anaesthetic. Amongst this group of patients $6(17 \%)$ had cardiovascular disease, 1 had gout and 4 (12\%) had osteoarthritic disease. Eight (22\%) were on some form of analgesics including aspirin, indomethacin, ibuprofen and naproxen. Two $(6 \%)$ of the patients were on oral steroids for polymyalgia (Table I). The age of the patients ranged from 58 to 88 years (mean 78.5 years). There were 22 women and 14 men.

Following $\mathrm{RBH}$, apart from receiving acetazolamide $500 \mathrm{mg}$ and a firm eye pad, none of the eyes required any further measures such as paracentesis. Of these 36 patients, 24 underwent early planned surgery within 2-4 days following $\mathrm{RBH}$. During the intervening period they had shown no decrease in visual acuity, their eyelid swelling and proptosis were noted to be subsiding, and there was no gross resistance to retropulsion of the globe digitally. In addition the ocular movements were not restricted, applanation tonometry was normal and the central retinal artery was noted to be patent at the optic disc. The other 12 patients were either not suitable for general anaesthesia or had declined early planned surgery under local anaesthetic following $\mathrm{RBH}$ and preferred longer postponement. Of the 24 patients who underwent early planned surgery following RBH, 17 had general anaesthesia while 7 had repeat local anaesthesia, 4 with peribulbar and 3 with repeat retrobulbar technique (Table II). All the patients had Honan's balloon or digital massage applied pre-operatively and after local anaesthesia to soften the globe. None of the patients who had repeat local anaesthesia developed further orbital haemorrhage. There were 22 cataract procedures with intraocular lens (IOL) implantation and 2 trabeculectomies. One of the cataract patients had intra-operative vitreous loss due to posterior capsule dehiscence, but had a successful anterior chamber IOL implant. No other adverse intra-operative complication occurred in any of the other cases. Post-operatively all the eyes had an uneventful course.

\section{DISCUSSION}

Despite current trends towards peribulbar and other forms of local anaesthetic techniques, ${ }^{2+4}$ retrobulbar anaesthesia remains one of the most commonly used local anaesthetic techniques in ophthalmic surgery. ${ }^{6.10 .11}$ With this technique a small volume of anaesthetic is required which usually

Table I. Associated conditions in patients who developed retrobulbar haemorrhage

\begin{tabular}{lrl}
\hline No. & $\%$ & Condition \\
\hline 6 & 17 & Cardiovascular disease \\
1 & 3 & Gout \\
4 & 12 & Osteoarthritic disease \\
8 & 22 & Analgesics \\
2 & 6 & Oral steroids \\
\hline
\end{tabular}

The total number of patients who developed retrobulbar haemorrhage was 36 . gives complete akinesia and anaesthesia in a relatively short period of time. However, the technique involves the insertion of a needle into a space occupied by a number of delicate neural and vascular structures, and various complications due to direct trauma of these structures can occur. ${ }^{6.12 .13}$ Amongst these, perhaps the most common is $\mathrm{RBH}$, with a reported incidence range of $1-3 \% .^{6.7}$

The orbital haemorrhage may vary in severity. Some cases are of venous origin and spread slowly. Surgery in such circumstances may not always be cancelled, and a recent report by Cionni and Osher ${ }^{14}$ showed no adverse complications in 57 such cases where small-incision surgery was safely completed despite the haemorrhage. Contrary to this, if the haemorrhage is of arterial origin then there is a rapid and tense orbital swelling with marked proptosis, immobility of the globe, inability to close the eyelid and massive bloodstaining of the lids and conjunctiva. To proceed with surgery in such circumstances would obviously be dangerous. Surgery has to be postponed but the question of when to re-operate has generally not been addressed.

The patients are usually discharged home the following day and re-listed for surgery under general anaesthesia ${ }^{9}$ a few weeks later. The prospect of long postponement of surgery may cause disappointment and anxiety for some patients. Our study showed that none of the 24 patients who had their planned surgery performed within 2-4 days following RBH had any adverse or unusual intra-operative or post-operative complications. Re-scheduling intraocular surgery under general anaesthesia is preferable, and during the additional stay at the hospital or on an outpatient basis, investigations preparatory to the anaesthesia

Table II. Details of the 24 patients who underwent early planned surgery following retrobulbar haemorrhage

\begin{tabular}{|c|c|c|c|c|c|}
\hline No. & $\begin{array}{l}\text { Age } \\
(\mathrm{yr})\end{array}$ & Sex & Surgery & $\begin{array}{c}\text { Repeat } \\
\text { anaesthesia }\end{array}$ & $\begin{array}{l}\text { Days interval } \\
\text { (after } \mathrm{RBH} \text { ) }\end{array}$ \\
\hline 1 & 74 & $\mathrm{M}$ & $\mathrm{ECLE}+\mathrm{IOL}$ & $\mathrm{LA}(\mathrm{PB})$ & 2 \\
\hline 2 & 71 & M & $\mathrm{ECLE}+\mathrm{IOL}$ & GA & 3 \\
\hline 3 & 68 & $\mathrm{~F}$ & $\mathrm{ECLE}+\mathrm{IOL}$ & $\mathrm{GA}$ & 2 \\
\hline 4 & 69 & $\mathrm{~F}$ & $\mathrm{ECLE}+\mathrm{IOL}$ & LA (RB) & 3 \\
\hline 5 & 76 & $\mathrm{~F}$ & $\mathrm{ECLF}+\mathrm{IOL}$ & GA & 3 \\
\hline 6 & 66 & M & $\mathrm{ECLE}+\mathrm{IOL}$ & GA & 3 \\
\hline 7 & 75 & $\mathrm{~F}$ & $\mathrm{ECLE}+\mathrm{IOL}$ & GA & 2 \\
\hline 8 & 74 & M & $\mathrm{ECLE}+\mathrm{IOL}$ & $\mathrm{LA}(\mathrm{PB})$ & 2 \\
\hline 9 & 80 & $\mathrm{M}$ & $\mathrm{ECLE}+\mathrm{IOL}$ & $\mathrm{LA}$ & 4 \\
\hline 10 & 79 & $\mathrm{~F}$ & $\mathrm{ECLE}+\mathrm{IOL}$ & GA & 2 \\
\hline 11 & 74 & $\mathrm{M}$ & Trab. & $\mathrm{LA}(\mathrm{PB})$ & 2 \\
\hline 12 & 71 & $\mathrm{~F}$ & $\mathrm{ECLE}+\mathrm{IOL}$ & GA & 3 \\
\hline 13 & 79 & M & $\mathrm{ECLE}+\mathrm{IOL}$ & GA & 3 \\
\hline 14 & 77 & $\mathrm{~F}$ & $\mathrm{ECLE}+\mathrm{IOL}$ & GA & 2 \\
\hline 15 & 88 & $\mathrm{~F}$ & Trab. & GA & 2 \\
\hline 16 & 59 & M & $\mathrm{ECLE}+\mathrm{IOL}$ & LA (PB) & 3 \\
\hline 17 & 86 & $\mathrm{~F}$ & $\mathrm{ECLE}+\mathrm{IOL}$ & GA & 4 \\
\hline 18 & 70 & $\mathrm{M}$ & $\mathrm{ECLE}+\mathrm{IOL}$ & GA & 3 \\
\hline 19 & 85 & $\mathrm{~F}$ & $\mathrm{ECLE}+\mathrm{IOL}$ & GA & 3 \\
\hline 20 & 79 & $\mathrm{~F}$ & $\mathrm{ECLE}+\mathrm{IOL}$ & $\mathrm{GA}$ & 3 \\
\hline 21 & 86 & $\mathrm{~F}$ & $\mathrm{ECLE}+\mathrm{IOL}$ & GA & 4 \\
\hline 22 & 80 & $\mathrm{~F}$ & $\overline{E C L E}+\mathrm{IOL}$ & GA & 2 \\
\hline 23 & 86 & $\mathrm{~F}$ & $\mathrm{ECLE}+\mathrm{IOL}$ & $\mathrm{LA}(\mathrm{RB})$ & 3 \\
\hline 24 & 71 & $\mathrm{~F}$ & $\mathrm{ECLE}+\mathrm{IOL}$ & $\mathrm{LA}(\mathrm{RB})$ & 2 \\
\hline
\end{tabular}

M, male; F, female; ECLE, extracapsular lens extraction: IOL, intraocular lens; Trab.. trabeculectomy; LA, local anaesthetic; PB, peribulbar; GA, general anaesthetic; RB, retrobulbar. 
and monitoring of the eye can be carried out. Seven of our patients were considered unsuitable for general anaesthesia and had their surgery under repeat local anaesthetic.

Four patients had peribulbar anaesthesia while 3 had repeat retrobulbar anaesthesia. All the patients had preoperative application of Honan's balloon with digital massage to soften the globe.

Our study has shown that it was quite safe to proceed with planned surgery as early as 2 days following RBH. All patients satisfied the following criteria:

1. No visual deterioration.

2. Decreasing proptosis and periorbital swelling.

3. Decreasing tenseness of the eyelids.

4. No resistance to retropulsion.

5. Eye movements not restricted.

6. Normal intraocular pressure.

7. Patent central retinal artery (this examination may not be possible in all cases depending on the density of the cataract).

In conclusion we feel that long postponement of surgery may not be essential in all cases following retrobulbar haemorrhage and that our report should help to allay anxiety both for the patient and for the surgeon deciding on when and on whom to proceed with planned surgery following this complication.

We would like to thank Mrs Lynda Rose for typing the manuscript.
Key words: Retrobulbar anaesthesia, Retrobulbar haemorrhage.

\section{REFERENCES}

1. Knapp H. On cocaine and its use in ophthalmic and general surgery. Arch Ophthalmol 1884;13:402-48.

2. Fry RA, Henderson J. Local anaesthesia for eye surgery: the periocular technique. Anaesthesia 1990;45:14-17.

3. Hawksworth NR, Joseph JP. Peribulbar anaesthesia. Br J Ophthalmol 1992;76:254.

4. Redmond RM, Dallas NL. Extracapsular cataract extraction under local anaesthesia without retrobulbar injection. $\mathrm{Br} \mathrm{J}$ Ophthalmol 1990;74:203-4.

5. Antoszyk AA, Bukley EG. Contralateral decreased visual acuity and extraocular muscle palsies following retrobulbar anaesthesia. Ophthalmology 1986:93:462-5.

6. Robert MF. Current concepts in retrobulbar anaesthesia. Surv Ophthalmol 1985;30:102-10.

7. Ellis PP. Retrobulbar injections. Surv Ophthalmol 1974:18:425-30.

8. Easty DL. Current ophthalmology surgery. London: Ballière Tindall, 1990:25.

9. Hanna IT. Audit of cataract surgery. The Scottish Office, NHS in Scotland. Audit Symposium, December 1991.

10. Nordan LT, Maxwell WA. The surgical rehabilitation of vision. London: Gower, 1992: chapter 5.

11. Joseph JP, McHugh JDA. Perforation of the globe: complication of peribulbar anaesthesia. $\mathrm{Br} \mathrm{J}$ Ophthalmol 1991;75:504-5.

12. Duker JS. Belmont JB. Inadvertent globe perforation during retrobulbar and peribulbar anaesthesia. Ophthalmology 1991;98:519-26.

13. Morgan CM. Schatz H. Ocular complications associated with retrobulbar injection. Ophthalmology 1988;95:660-5.

14. Cionni RJ, Osher RH. Retrobulbar haemorrhage. Ophthalmology 1991:98:1153-5. 